\title{
LA TIERRA EN CUBA. \\ BIBLIOGRAFÍA BÁSICA, FUENTES \\ Y PERSPECTIVAS DE ESTUDIO
}

\author{
Imilcy Balboa \\ Reinaldo Funes*
}

$\mathrm{L}$

a historiografía cubana ha estado dominada por grandes bloques temáticos que han conducido y marcado los estudios históricos. Durante la primera mitad del siglo XX predominaron las cuestiones relacionadas con la formación de la nacionalidad y el Estado nación, en especial las guerras por la independencia y las grandes personalidades que con su pensamiento o su acción contribuyeron a la creación de la república, inaugurada el 20 de mayo de 1902. Sin dejar de atenderse estos temas, durante la segunda mitad del siglo se asistió al despunte de las historias socioeconómicas con particular atención -sobre todo después de la revolución de 1959- al proceso de la esclavitud y el florecimiento del monocultivo azucarero en la isla. El examen de las raíces históricas de la nueva etapa volvía a acaparar la atención de gran parte de los historiadores.

En realidad, el marco temático se ha correspondido también, de una u otra forma, con el desarrollo de la historiografia a nivel mundial. El conocimiento de la historia de Cuba se ha visto enriquecido con los aportes de especialistas extranjeros, en especial de España y Estados Unidos, menos apremiados por las urgencias del discurso nacionalista. Los nexos con el acontecer historiográfico internacional pueden constatarse, además, con la diversidad de temas abordados durante las décadas de 1980 y 1990, como el estudio de las industrias alternativas, la inmigración, la mujer, las organizaciones obreras, la criminalidad

* Imilcy Balboa, Instituto de Historia, CSIC, Madrid. Reinaldo Funes, Fundación Antonio Núñez Jiménez de la Naturaleza y el Hombre, La Habana (Trabajo realizado dentro del proyecto de investigación, BHA 2000-1334, en una estancia de investigación financiada por la Secretaría de Estado, de Educación y Universidades, SB 2000-0045.) 
o las implicaciones medioambientales del desarrollo azucarero, cuestionando viejas explicaciones y proponiendo nuevos análisis del pasado.

Dentro de las líneas generales expuestas, la cuestión de la tierra -máxime si consideramos su condición de país eminentemente agrícola- no ha estado ausente en las miradas a la evolución histórica, aunque con desigual énfasis. La preocupación por el tema agrario en general, y de la tierra en particular, creció de forma paralela con el auge de las historias socioeconómicas. No se pueden entender las directrices de la economía en los primeros siglos coloniales, los avances de la agricultura, las características de los cultivos, la preeminencia del azúcar y el rumbo diferente que a partir del llamado boom azucarero de fines del siglo XVIII y principios del siglo XIX asumió la ordenación agraria y el desarrollo económico en el occidente y el oriente del país, los asentamientos poblacionales, así como la propia política de colonización, por sólo citar algunos ejemplos, sin conocer la estructura agraria, las formas de explotación y tenencia de la tierra, así como su proyección e incidencia en la economía y la sociedad tanto a nivel regional como en el conjunto insular.

En el presente trabajo pretendemos poner a disposición del lector un resumen de los principales aportes historiográficos, además de señalar las carencias y perspectivas de estudio. ${ }^{1}$ Aun cuando el tema no quede agotado, esperamos que constituya una orientación de utilidad para futuras investigaciones sobre la tierra y su problemática en Cuba.

\section{Presencia DE LA TIERRA EN LAS OBRAS DE CARÁCTER GENERAL}

En primer lugar analizaremos las historias generales o las historias económicas en las cuales podemos encontrar referencias útiles sobre la organización agraria. No fue sino hasta mediados del siglo XX cuando esta problemática pasó a formar parte explícita de las obras de carácter histórico. En la Historia de la nación cubana publicada en 1952, el tema de la tierra se incorporó por primera vez de una manera profunda y sistemática en una obra de carácter general. En la parte correspondiente a la economía, Julio Le Riverend concede una importancia central a la formación de la estructura agraria como la base de la organización de la isla. A lo largo del texto nos ofrece información primordial sobre las formas de propiedad y explotación de la tierra, respondiendo viejas interrogantes y apuntando hipótesis que todavía mantienen plena vigencia. Estos capítulos conforman lo fundamental de lo que se convertiría en una de las obras históricas más editadas y en muchos sentidos no superada, su Historia económica de Cuba.

\footnotetext{
${ }^{1}$ No hemos incluido en el presente artículo el estudio de los cultivos, salvo cuando en los trabajos analizados se examinan en relación con la tierra, pues las obras dedicadas al azúcar, el tabaco o el café, excederían los límites de este trabajo y ameritan un análisis particular.
} 
Cada uno de los capítulos, dedicados al examen de un periodo concreto (16971790, 1790-1837, 1837-1868, 1868-1902, 1902-1951), comienza con un análisis de la estructura y las transformaciones sufridas en el ámbito agrario, ofreciéndonos a continuación un amplio reconocimiento del entramado socioeconómico y su evolución durante los años señalados. ${ }^{2}$

El otro gran ejemplo de la inserción de la tierra como elemento central en la evolución socioeconómica de Cuba lo constituye la obra de Leví Marrero, Cuba, economía y sociedad, que comprende desde la época precolombina hasta el año 1868, y en varios de sus quince tomos dedica diferentes capítulos o epígrafes al estudio de las formas de propiedad y explotación de la tierra. Marrero, además de la información de las actas del Cabildo de La Habana, aporta una amplia documentación procedente del Archivo General de Indias para ilustrarnos acerca de la cesión de terrenos por parte de los Cabildos y el proceso de legitimación de la propiedad y su subdivisión en los siglos XVII y XVIII hasta las primeras décadas del XIX, cuando la corona reconoció la propiedad plena sobre la mayor parte de las mercedes concedidas con anterioridad. De la misma manera aparecen otros aspectos relacionados con la temática, como la evolución de la ganadería, la agricultura comercial y los cultivos de subsistencia, o asuntos escasamente abordados por la historiografía cubana, como la incidencia en la isla del proceso de desamortización que se desarrolló en España a lo largo del siglo XIX. ${ }^{3}$

Otras historias generales e historias económicas de Cuba escritas en el siglo XX nos brindan información sobre el tema de la tierra. Entre ellas habría que mencionar el Manual de historia de Cuba de Ramiro Guerra, donde podemos encontrar datos interesantes en cuanto al régimen agrario existente hasta 1868, y la Historia económica de Cuba, publicada en 1944 por el alemán Heinrich Friedlaender, que aporta aspectos de importancia para comprender los cambios en la propiedad y usos de la tierra en relación con las concepciones económicas en boga. ${ }^{4}$

La más reciente obra colectiva, la Historia de Cuba, coordinada por el Instituto de Historia de Cuba, dedica varios capítulos al análisis de la estructura agraria en cada uno de los tres tomos aparecidos hasta el momento. En el primer tomo -hasta 1867- se abordan los repartimientos iniciales, la formación social

2 Véanse Ramiro Guerra et al., Historia de la nación cubana, Editorial Historia de la Nación Cubana/Academia de la Historia de Cuba, La Habana, 1952, 10 vols.; Julio Le Riverend, Historia económica de Cuba, Instituto Cubano del Libro, La Habana, 1971.

${ }^{3}$ Leví Marrero, Cuba, economía y sociedad, Editorial Playor, Madrid, 1971-1992, 15 vols. Por su tratamiento particular y de forma más profunda, véase especialmente "La tierra", epígrafe 2, tomo 2; “La tierra aprobación y utilización", epígrafe 3, tomo 3; "La tierra. Los límites de la apropiación", epígrafe 3, tomo 6, y "La tierra, propiedad y utilización", epígrafe 3, tomo 10.

${ }^{4}$ Ramiro Guerra, Manual de historia de Cuba, Ciencias Sociales, La Habana, 1971; Heinrich Friedlaënder, Historia económica de Cuba, Jesús Montero Editor, La Habana, 1944. (Existe una segunda edición por la Editorial de Ciencias Sociales, La Habana, 1978.) 
derivada de ellos y la estructura agraria a partir de las grandes haciendas ganaderas y la posterior y limitada irrupción de la agricultura comercial alrededor de los primeros núcleos urbanos. Cabe destacar, por los elementos novedosos, los capítulos III y IV escritos por Arturo Sorhegui y Alejandro de la Fuente, sobre todo con respecto a la formación de la oligarquía de la tierra: los señores de hatos, aunque su examen se refiere fundamentalmente a La Habana y se resiente para el resto de la isla. En cuanto a las fuentes, se aportan en ambos capítulos reveladoras estadísticas confeccionadas a partir del Fondo de Anotaduría de Hipotecas, existente en el Archivo Nacional de Cuba.

Se distingue también por su enfoque el capítulo VI, a cargo de Gloria García, dedicado a la caracterización de la estructura agraria entre 1763 y 1850, donde se examina la demolición de las grandes haciendas a partir de la expansión azucarera, las implicaciones de este proceso no sólo a nivel insular, sino también regional en interrelación con los distintos tipos de fincas, los usos de la tierra, extensión de las propiedades agrarias, la producción y los rendimientos agrícolas, comercialización de los frutos, la población, etc. También en el capítulo IX, dedicado al análisis de la crisis de la economía esclavista, García, junto a Orestes Gárciga, nos informan sobre los cultivos, valor bruto de lo producido según el tipo de finca, distribución de la renta líquida, etcétera.

En el segundo tomo, que abarca el periodo de 1868 a 1898 y con especial atención en las guerras por la independencia, se vuelve a dedicar un espacio a las cuestiones agrarias. En el acápite titulado, "El desarrollo capitalista en los albores de la época imperialista", Fe Iglesias estudia específicamente el proceso de concentración y centralización de la industria azucarera, los cambios en la propiedad y la penetración de capitales extranjeros en la agricultura. Por último, en el tercer tomo -de los cinco proyectados- que aborda el periodo de 1899 a 1940 , se analiza la tierra fundamentalmente en relación con la industria del azúcar en sus vertientes económica y social: la expansión del latifundio, la burguesía azucarera y la fuerza de trabajo en el campo. Al final de cada tomo, en los anexos estadísticos, encontramos datos sobre el número de fincas, su renta líquida, etcétera. ${ }^{5}$

Finalmente al hablar de los estudios de carácter general sobre el tema de la tierra en Cuba no se pueden olvidar aquellas que examinan el contexto latinoame-

${ }^{5}$ Instituto de Historia de Cuba, Historia de Cuba. La colonia, evolución socioeconómica y formación nacional. De los orígenes hasta 1867, Ed. Política, La Habana, 1994, t. 1; Historia de Cuba. Las luchas por la independencia nacional y las transformaciones estructurales. 1868-1898, Ed. Política, La Habana, 1996, t. 2; Historia de Cuba. La neocolonia. Organización y crisis. Desde 1899 hasta 1940, Ed. Política, La Habana, 1998, t. 3. Sobre los trabajos citados en el texto Arturo Soreghi y Alejandro de la Fuente, "El surgimiento de la sociedad criolla de Cuba (1553-1608)", t. 1, cap. III, pp. 107-138, y "La organización de la sociedad criolla (1608-1699)", t. 1, cap. IV, pp. 139179; Gloria García, "El auge de la sociedad esclavista en Cuba", t. 1, cap. vI, pp. 225-264; Gloria García y Orestes Gárciga, "El inicio de la crisis de la economía esclavista", t. 1, cap. IX, pp. 360-400; Fe Iglesias, "El desarrollo capitalista en los albores de la época imperialista", cap. IV, pp. 156-208. En el tomo tercero ver los caps. I, II, III, IV y VI. 
ricano en su conjunto, como es el caso de las obras de José María Ots Capdequí, El régimen de la tierra en la América española y El régimen de tierras en la época colonial. ${ }^{6}$

\section{FUENTES IMPRESAS Y BIBLIOGRAFÍA BÁSICA}

Los clásicos del siglo XIX, como Ramón de la Sagra, Miguel Rodríguez Ferrer, Jacobo de la Pezuela, José María de la Torre, Francisco Frías y Jacott o Álvaro Reynoso, hacen referencia de una u otra forma a la problemática de la tierra. No obstante es necesario establecer una diferenciación: las obras de los primeros tienen un carácter más general, mientras los dos últimos, Frías y Reynoso, al igual que otros científicos y agrónomos de la época, ponen más énfasis en las cuestiones relacionadas con las transformaciones y reformas necesarias en el agro, sobre todo en lo referente al cultivo e industria del azúcar. ${ }^{\text {? }}$

Las referencias más importantes las podemos encontrar en libros ligados de una u otra forma a los complejos problemas relacionados con la delimitación y reconocimiento pleno de la propiedad privada. Durante el siglo XIX, al mismo tiempo que se intensificaban las labores de agrimensura en la isla, vieron la luz diferentes obras dedicadas a esclarecer los límites y legitimidad de las posesiones rurales, con el objeto de aportar claridad en los conflictos en torno a la propiedad sobre la tierra y, en especial, orientar el trabajo de los agrimensores. Tales fueron los casos de Agrimensura aplicada al sistema de medidas de la isla de Cuba, publicada por Desiderio Herrera en 1835, y del Manual de agrimensura cubana escrito por Rodrigo Bernardo y Estrada en 1854. Este autor escribió varios años más tarde el Prontuario de mercedes concedidas por el excelentísimo Ayuntamiento de La Habana en cuanto concierne a las haciendas de crianza de animales, una recopilación útil de los datos existentes sobre las haciendas mercedadas en la isla hasta 1729, fecha en que se le prohibió a los Cabildos con-

${ }^{6}$ María Ots Capdequí, El régimen de la tierra en la América española durante el periodo colonial, Universidad de Santo Domingo, Ciudad Trujillo, 1946, y España en América. El régimen de tierras en la época colonial, Fondo de Cultura Económica, México, 1959.

7 Véanse Ramón de la Sagra, Historia económico-política y estadística de la isla de Cuba, Imprenta de las Viudas de Arazoza y Soler, La Habana, 1831, y Cuba: 1860 o sea cuadro de sus adelantos en la población, la agricultura, el comercio y las rentas públicas, Librería de L. Hachette y Cía., París, 1862. (Existe otra edición de la Comisión Nacional Cubana de la UNESCO, La Habana, 1963.) Jacobo de la Pezuela, Diccionario geográfico, estadístico, histórico de la isla de Cuba, Imprenta del Establecimiento de Mellado, Madrid, 1865-1866, e Historia de la isla de Cuba, Impresión de Carlos Bailly-Baillier, Madrid, 1868, 4 vols.; Miguel Rodríguez Ferrer, Naturaleza y civilización de la grandiosa isla de Cuba, Imprenta de J. Noguera a cargo de M. Martínez, Madrid, 1876; Francisco Frías y Jacott, conde de Pozos Dulces, Reformismo agrario, Publicaciones de la Secretaría de Educación, Dirección de Cultura, La Habana, 1937; Álvaro Reynoso, Ensayo sobre el cultivo de la caña de azúcar, Ministerio de Industrias/Editorial Nacional de Cuba, La Habana, 1963. 
tinuar con esta práctica. Aparecen aquí no sólo los hatos y corrales mercedados, sino también sus propietarios y la fecha de demolición, en los casos en que ésta ya se había producido. En 1863 vio la luz Nociones de agrimensura legal de la isla de Cuba de Esteban Tranquilino Pichardo y Jiménez, uno de los libros más consultados por los estudiosos del tema agrario por la variedad de datos que aporta. Una nueva versión de este trabajo, ampliado y aumentado por el mismo autor, apareció en $1902 .^{8}$

El interés por las cuestiones relacionadas con la propiedad de la tierra tuvo a principios del siglo $\mathrm{XX}$ cierto auge, quizás relacionado con la necesidad de su esclarecimiento en la nueva coyuntura económica de la isla a partir de las singulares relaciones de dependencia económica y política respecto a Estados Unidos tras el fin de la soberanía española. La reedición de la obra de Esteban Pichardo podría verse como un ejemplo de esa inclinación. También Leopoldo Cancio, José Rafael Gómez y Benito Celorio centraron su atención en las cuestiones legales y las haciendas comuneras, precisamente las figuras agrarias que estaban entorpeciendo el acceso a la propiedad plena. ${ }^{9}$ El tema no fue abandonado y a los anteriores se suman los trabajos de varios autores estadunidenses como R. Whitbeck, Dubon Corbitt y Lowry Nelson, dedicados al examen de la agricultura, y especialmente las mercedes de tierras, los realengos y los latifundios. ${ }^{10}$

Precisamente los latifundios, que alcanzarían su máxima expresión durante el vertiginoso crecimiento azucarero en el primer cuarto de siglo de vida republicana gracias a las grandes inversiones de capitales estadunidenses en el sector, incluyendo la compra de inmensas extensiones de tierras en las provincias de Camagüey y Oriente, en la mitad oriental de la isla, constituyeron el centro de varios estudios realizados en la primera mitad del siglo XX. En el listado de títulos no podría faltar Azúcar y población en las Antillas, en la que Ramiro Guerra

${ }^{8}$ Desiderio Herrera, Agrimensura aplicada al sistema de medidas de la isla de Cuba, La Habana, 1835; Rodrigo Bernardo y Estrada, Manual de agrimensura cubana, Imprenta de la Hoja Económica, Sagua la Grande, 1854, y Prontuario de mercedes concedidas por el excelentisimo Ayuntamiento de La Habana en cuanto concierne a las haciendas de crianza de animales, Establecimiento Tipográfico La Cubana, La Habana, 1857; Esteban Tranquilino Pichardo y Jiménez, Nociones de agrimensura legal de la isla de Cuba, Imprenta y Librería Militar, La Habana, 1863; Agrimensura legal en la isla de Cuba, segunda edición corregida y aumentada, Imprenta y Librería Antigua de Valdepares, La Habana, 1902.

${ }^{9}$ Leopoldo Cancio Luna, "Haciendas comuneras", Cuba y América, núm. 6, 1902, La Habana, pp. 227-236; José Rafael Gómez Cañizares, Historia, deslinde y reparto de haciendas comuneras, Imprenta J. Berenguer, Santa Clara, 1910; Benito Celorio y Alfonso, Las haciendas comuneras, Imprenta de Rambla y Bouza, La Habana, 1914.

${ }^{10}$ R. H. Whitbeck, "Geographical relations in the development of Cuban agriculture", Geographical Review, núm. 12, vol. 2, 1911, Nueva York, pp. 222-240; Dubon Corbitt, "Mercedes and realengos in Cuba: a survey of the public land system in Cuba", Hispanic American Historical Review, núm. 19, vol. 3, 1939, Durham, pp. 262-285; Lowry Nelson, "The evolution of the Cuban land system", Land Economics, vol. xxv, núm. 4, 1949, Madison, pp. 365-381, y Rural Cuba, University of Minnesota Press, Minesota, 1950. 
analiza -y denuncia- los efectos del latifundio en el agro cubano, así como el análisis de Raúl Maestri en El latifundismo en la economía cubana. ${ }^{11}$

La obra de Manuel Moreno Fraginals, aun cuando su tema principal es el azúcar, contiene información útil para entender las transformaciones sufridas en la agricultura. El ingenio $^{12}$ nos adentra no sólo en el conocimiento de la producción azucarera, sino también en su relación con la tierra, los bosques y la población. De igual forma otros trabajos históricos que se ocupan de la evolución de la industria azucarera analizan el tema de la tierra. La lista sería muy extensa, pero por su importancia merece ser destacado Cuando reinaba su majestad el azúcar, escrito por Roland T. Ely, donde entre otras cuestiones encontramos información novedosa en el epígrafe dedicado a la pérdida de fertilidad de los suelos. ${ }^{13}$

Los trabajos dedicados al resto de los cultivos y actividades rurales en general son escasos en comparación con los que se ocupan del mundo azucarero, pero también aportan elementos importantes para la problemática de la tierra. Entre los que centran su objetivo en la producción tabacalera en la isla tenemos la obra pionera de José Rivero Muñiz, Tabaco, su historia en Cuba, que profundiza en aspectos como el conocimiento del régimen de explotación rural y la situación de los vegueros; también Jean Stubbs, Tabaco en la periferia. El complejo agro-industrial cubano y su movimiento obrero, 1860-1959, incorpora información sobre el problema de la tierra en la producción de tabaco. Por su parte, Francisco Pérez de la Riva se adentra en el mundo de la explotación cafetalera. ${ }^{14}$

A este último autor debemos el primer estudio dedicado íntegramente a la problemática de la tierra. Su trabajo de ingreso como académico correspondiente de la Academia de la Historia de Cuba titulado Origen y régimen de la propiedad territorial en Cuba, publicado en 1946, analiza las características que desde los inicios asumió el orden rural en relación con la posesión del suelo y su proyección en el tiempo. ${ }^{15}$ A él se suman dos investigaciones de Julio Le Riverend

"Ramiro Guerra y Sánchez, Azúcar y población en las Antillas, Minerva, La Habana, 1827. (Entre otras reediciones se puede citar la de la Editorial Ciencias Sociales de 1970.) Raúl Maestri y Arredondo, El latifundismo en la economía cubana, Editorial Hermes, La Habana, 1929.

${ }^{12}$ Manuel Moreno Fraginals, El ingenio. Complejo económico social cubano del azúcar, Ciencias Sociales, La Habana, 1978, 3 tomos.

${ }^{13}$ Roland T. Ely, Cuando reinaba su majestad el azúcar. Estudio histórico-sociológico de una tragedia latinoamericana, el monocultivo en Cuba. Origen y evolución del proceso, Editorial Sudamericana, Buenos Aires, 1963.

${ }^{14}$ Véase José Rivero Muñiz, Tabaco, su historia en Cuba, Instituto de Historia/Academia de Ciencias de Cuba, La Habana, 1965, 2 tomos; Jean Stubbs, Tabaco en la periferia. El complejo agro-industrial cubano y su movimiento obrero, 1860-1959, Ciencias Sociales, La Habana, 1989, y Francisco Pérez de la Riva, El café: historia de su cultivo y explotación en Cuba, Ed. Jesús Montero, La Habana, 1944.

${ }^{15}$ Francisco Pérez de la Riva, Origen y régimen de la propiedad territorial en Cuba, La Habana, Imprenta el Siglo XX, 1946. 
ligadas a diferentes etapas de El Colegio de México, institución en la que este importante historiador cubano cursó estudios de doctorado. El primero, Los orígenes de la economía cubana, apareció en 1945, mientras el segundo fue publicado en 1970 bajo el título "Problemas del régimen de apropiación de la tierra". 16

Tendrían que pasar varios años para que la temática volviera a adquirir protagonismo en un nuevo trabajo de Le Riverend: Problemas de la formación agraria de Cuba, siglos XVI-XVIII-aparecido primero en forma de artículos-y que puede considerarse la obra fundamental sobre la estructura agraria en Cuba. El libro nos ofrece un recorrido magistral por la estructura y explotación rural de la isla durante los primeros siglos, donde se precisan y explican las diferentes formas que adoptó la organización agraria -vecindades, montones de yuca, hatos corrales, sitios y estancias- junto a los bienes y derechos comunales -especialmente los ejidos. Asimismo analiza el sistema jurídico en contraste con el régimen de apropiación, explicando el papel de los cabildos y la aptitud de la corona ante las mercedes de tierras, "el hecho consumado", las reales cédulas confirmando o revocando la propiedad. También examina las transformaciones agrarias -subdivisión de las haciendas-sin olvidar sus consecuencias sociales: los conflictos por la propiedad, las pugnas entre los hacendados ganaderos y azucareros y entre éstos y los pequeños cultivadores, en especial los vegueros, la estratificación de la sociedad, etc., así como también los cambios en los usos de la tierra, las variantes de explotación agrícola, la tecnología y las relaciones entre la cuidad y el campo. El libro se complementa además, con un panorama general de la situación agraria del siglo XVIII, que incluye un examen diferenciado entre el ámbito regional y un bosquejo del régimen agrario en otras colonias europeas. ${ }^{17}$

Juan Pérez de la Riva llevó este análisis al ámbito particular al indagar la historia del latifundio de Puercos Gordos y El Salado, cuyo seguimiento a través de tres siglos nos revela las transformaciones sufridas desde la concesión de la merced en 1657 hasta el establecimiento de una granja del pueblo después de 1959. Dentro de las historias locales también contamos con el trabajo de Hortensia Pichardo, que reconstruye la historia del poblado de Jiguaní, en la región oriental de Cuba, uno de los pocos núcleos de población aborigen -los llamados

${ }^{16}$ Julio Le Riverend, Los orígenes de la economía cubana, El Colegio de México, México, 1945; "Problemas del régimen de apropiación de la tierra" en B. García Martínez et al., Historia y sociedad, El Colegio de México, México, 1970, pp. 79-94.

${ }^{17}$ Julio Le Riverend, Problemas de la formación agraria de Cuba, siglos XVI- XVII, Ciencias Sociales, La Habana, 1992. También bajo el mismo título ver la serie publicada por la Revista de la Biblioteca Nacional, núm. 1, enero-marzo, 1984, La Habana, pp. 155-185; núm. 2, mayo-agosto, 1984, pp. 139-176; núm. 3, septiembre-diciembre, 1984, pp. 161-193; núm. 1, enero-abril, 1985, pp. 177-201; núm. 2, mayo-agosto, 1985, pp. 157-180, núm. 3, septiembre-diciembre, 1985, pp. 181200; núm. 1, enero-abril, 1986, pp. 93-121; núm. 2, mayo-agosto, 1986, pp. 157-194; núm. 3, septiembre-diciembre, 1986, pp. 157-196. 
pueblos de indios-incluyendo la distribución de las tierras y las luchas por su explotación y dominio. Aunque de forma más general, Le Riverend también hace alusión a la situación agraria de una localidad en La Habana, biografia de una provincia..$^{18}$ Estos trabajos han tenido como antecedentes las investigaciones sobre territorios específicos, como las de Irene Wright dedicada a la villa de La Habana y su región en los primeros siglos coloniales, la de Juan Torres Lasquetti para el territorio camagüeyano, así como los de Martínez Fortún y Emilio Bacardí para Remedios y la zona oriental respectivamente. ${ }^{19}$

\section{CONTINUIDAD Y NUEVAS LÍNEAS DE INVESTIGACIÓN. ÚLTIMAS TENDENCIAS DE LOS ESTUDIOS SOBRE EL TEMA DE LA TIERRA}

Los estudios emprendidos por Le Riverend o por los hermanos Pérez de la Riva han tenido continuidad en una serie de publicaciones que aportan o amplían el conocimiento de determinados aspectos de la problemática agraria, fundamentalmente en el periodo colonial. Los trabajos de Arturo Sorhegui y Gloria García -como hemos visto anteriormente al referirnos a la Historia de Cuba-aportan datos importantes sobre la oligarquía hatera y los cambios ocurridos entre fines del siglo XVIII y las primeras décadas del XIX. Por su parte, Iglesias cuenta en su trayectoria con una serie de artículos sobre la temática, donde analiza desde la estructura agraria de La Habana en las postrimerías del siglo XVII hasta cuestiones relacionadas con el usufructo de la tierra a fines del siglo XIX, las transformaciones sufridas por el régimen de explotación, la subdivisión de la tierra y la incorporación de los pequeños productores - colonos--, atendiendo al examen de la distribución de los suelos según los diferentes cultivos, la situación de los labradores en relación con la posesión del terreno - propietarios o arrendatarios-, etc. Su libro Del ingenio al central profundiza en el conocimiento del proceso de concentración y centralización de la industria azucarera. ${ }^{20}$

${ }^{18}$ Juan Pérez de la Riva, "Tres siglos de historia de un latifundio cubano: Puercos Gordos y El Salado" en El barracón y otros ensayos, Ciencias Sociales, La Habana, 1975, pp. 91-124; Hortensia Pichardo, "Los orígenes de Jiguani" en Facetas de nuestra historia, Ed. Oriente, Santiago de Cuba, 1989, pp.77-100; Julio Le Riverend, La Habana. Biografia de una provincia, Imprenta el Siglo XX, La Habana, 1960.

19 Veánse Irene Aloa Wright, Historia documentada de San Cristóbal de La Habana en el siglo XVI: basada en documentos originales existentes en el Archivo General de Indias en Sevilla, Academia de la Historia de Cuba, La Habana, 1927, 2 tomos; Juan Torres Lasqueti, Colección de datos históricos, geográficos y estadísticos de Puerto Príncipe y su jurisdicción, Imp. El Retiro, La Habana, 1883; José A. Martínez Fortún y Foyo, Anales y efemérides de San Juan de los Remedios y su jurisdicción, Pérez Sierra y Cía., La Habana, 1930-1931; Emilio Bacardí y Moreau, Crónicas de Santiago de Cuba, Tipografía Arroyo y Hermanos, Santiago de Cuba, 1913-1925.

${ }^{20}$ Ver también Arturo Sorhegui, "El surgimiento de una aristocracia colonial en el occidente de Cuba durante el siglo XVI", Santiago, núm. 37, marzo, 1980, pp. 147-209; Fe Iglesias, "Algunos 
Otra línea de investigación que ha ganado protagonismo y que constituye una fuente de información para el estudio del tema de la tierra en Cuba viene de las historias regionales y locales (bien de provincias, municipios o territorios más pequeños). No obstante debemos señalar que en muy pocos casos la estructura de la propiedad y las cuestiones agrarias en general constituyen el centro de atención de dichos trabajos. En este apartado destacan los estudios de Hernán Venegas y Orlando Martínez que hacen referencia al problema de la tierra, siguiendo el proceso de expansión azucarera en la región central de la isla. Por su parte Nelson Oliva y Ángel Velázquez centran su atención en la zona oriental; su trabajo sobre la reconstrucción de la historia del poblado de Campechuela aporta interesantes datos sobre los cambios en la estructura agraria y las relaciones de propiedad en el territorio. A estos autores debemos además una indagación sobre la hacienda ganadera en Bayamo entre 1800 y $1850 .{ }^{21}$

En los últimos años, además, varios investigadores, desde diferentes postulados y perspectivas metodológicas, han emprendido estudios novedosos que ahondan en distintas facetas de la problemática agraria. Mercedes García, al analizar la distribución de los ingenios habaneros del siglo XVIII, nos informa sobre el proceso de deslinde y venta de tierras, la división interna de los terrenos de las fábricas según su uso o función, su valor y las condiciones del crédito. Asimismo su libro Misticismo y capitales ahonda en una faceta apenas conocida: las propiedades de los jesuitas en Cuba, y nos ofrece datos interesantes sobre los predios rurales de la orden. ${ }^{22}$

Los problemas agrarios y las investigaciones de la tierra en general, están presentes desde la historia de la ciencia en los trabajos de Rolando Misas, que indaga sobre los proyectos y programas de desarrollo agrario en diferentes

aspectos de la distribución de la tierra en 1899", Santiago, núm. 40, diciembre de 1980, pp. 119-178; "La estructura agraria de La Habana, 1770-1775", Arbor, núms. 547-548, vol. cXxxıx, julio-agosto de 1991, pp. 91-112; "La tierra en Cuba y Puerto Rico en 1899", Iberoamericana Pragencia, suplemento 5, 1991, pp. 125-144; Del ingenio al central, Editorial de la Universidad de Puerto Rico, Puerto Rico, 1998.

${ }^{21}$ Hernán Venegas Delgado, "Apuntes sobre la decadencia trinitaria en el siglo XIX", Islas, núm. 46, septiembre-diciembre, 1973, pp. 159-251; "Consideraciones en torno a la economía remediana colonial", Islas, núm. 67, septiembre-diciembre, 1980, pp. 11-79; "Acerca del proceso de concentración y centralización de la industria azucarera en la región remediana a fines del siglo XIX", Islas, núm. 73, septiembre-diciembre, 1982, pp. 63-121, y "Notas críticas sobre la economía colonial de Villa Clara", Islas, núm. 81, mayo-agosto, 1985, pp. 16-88; Orlando Martínez, "Estudio de la economía cienfueguera desde la fundación de la colonia Fernandina de Jagua hasta mediados del siglo XIX", Islas, núms. 55-56, septiembre de 1976-abril de 1977, pp. 117-169; Nelson Oliva y Ángel Velázquez, Campechuela. Origen y desarrollo hasta 1899, Impreso en la Fábrica José Joaquín Palma, Bayamo, 1989, y La hacienda ganadera en Bayamo, 1800-1850. Ciencias Sociales, La Habana, 1996.

${ }_{22}$ Mercedes García, "Ingenios habaneros en el siglo XvIII", Arbor, vol. cxxxIX, núms. 547-548, julio-agosto de 1991, pp. 113-138; "El crédito hipotecario a los ingenios habaneros: 1700-1792" en José A. Piqueras (ed.), Diez nuevas miradas de historia de Cuba, Publicacions de la Universitát Jaume I, Castelló de la Plana, 1998, pp. 41-66; Misticismo y capitales. La compañia de Jesús en la economia habanera del siglo XVIII, Ciencias Sociales, La Habana, 2000. 
momentos de la historia de la nación, y en los de Leida Fernández acerca de la implantación en la isla de una agricultura científica, especialmente durante la segunda mitad del siglo XIX. ${ }^{23}$ También en relación con la historia de la ciencia y la historia agraria contamos con los estudios de Consuelo Naranjo, Armando García y Mercedes Valero, que abordan una de las aristas sociales del problema, en especial los aspectos raciales, culturales e ideológicos de la inmigración al campo y el tipo de inmigrante más conveniente en relación con la idea que ostentaban algunos sectores acerca de la cubanidad y la conveniencia del blanqueamiento. ${ }^{24}$ Por su parte Carlos Venegas, en un artículo de reciente factura, rastrea la pequeña propiedad agraria -sitios de labor y estancias- en las publicaciones del siglo XIX..$^{25}$

Imilcy Balboa ha estudiado la relación entre la tierra, la fuerza de trabajo y las políticas de colonización emprendidas en la segunda mitad del siglo XIX. Su libro Los brazos necesarios, analiza el problema de la mano de obra en el agro, tanto en su vertiente campesina como asalariada, y su conexión con las condiciones económicas regionales, al tiempo que estudia la desamortización y reparto de baldíos y realengos - una experiencia colonizadora inédita hasta entonces-, el interés del Estado por validar su patrimonio y los conflictos entre éste, los municipios, los particulares y los pequeños propietarios por hacerse con la propiedad rústica. Asimismo, los cambios en el panorama agrario ocurridos a partir del proceso de concentración y centralización de la industria azucarera y las nuevas condiciones del mercado laboral durante y tras la abolición de la esclavitud, los usos alternativos del suelo, etcétera. ${ }^{26}$

${ }^{23}$ Rolando Misas, El trigo en Cuba: primera mitad del siglo XIX, Editorial Academia, La Habana, 1993; "La agricultura comercial en el proyecto expedicionario de Mopox a Cuba", Revista Complutense de Historia de América, núm. 20, 1994, Madrid, pp. 277-287; "La Real Sociedad Patriótica de La Habana y las investigaciones científicas aplicadas a la agricultura. (Esfuerzos de institucionalización: 1763-1864)" en Consuelo Naranjo y Tomás Mallo (eds.), Cuba la perla de las Antillas, Doce Calles, Madrid/Aranjuez, 1994, pp. 75-84, y "La ciencia en el programa de desarrollo agrario del conde de Pozos Dulces (1857-1858)" en José A. Piqueras (ed.), Diez nuevas miradas de historia de Cuba, pp. 91-114; Leida Fernández, "La agricultura cubana a fines del siglo XIX: ciencia y economía" en Francisco Morales Padrón (coord.), XIII Coloquio de Historia Canario Americana. III Congreso Internacional de Historia de América AEA, 1998, Ediciones del Cabildo de Gran Canaria, Las Palmas de Gran Canaria, 2000, pp. 422-434.

${ }^{24}$ Ver por ejemplo, Consuelo Naranjo, "Trabajo libre e inmigración española en Cuba: 18801930", Revista de Indias, vol. LII, núms. 195/196, 1992, pp. 749-794; "Hispanización y defensa de la integridad nacional en Cuba, 1868-1898”, Tiempos de América, núm. 2, 1998, pp. 71-91; C. Naranjo y Armando García, Racismo e inmigración en Cuba en el siglo XIX, Doce Calles, Aranjuez/Madrid, 1996; C. Naranjo y Mercedes Valero, "Trabajo libre y diversificación agrícola en Cuba: una alternativa a la plantación (1815-1840)", Anuario de Estudios Americanos, núm. 2, t. LI, 1994, pp. 113-133.

${ }^{25}$ Carlos Venegas Fornias, "Estancias y sitios de labor: su presencia en las publicaciones cubanas del siglo XIX", Colonial Latin American Historical Review, invierno de 2001, pp. 27-59.

${ }^{26}$ Imilcy Balboa, Los brazos necesarios. Inmigración, colonización y trabajo libre en Cuba, 1878-1898, Centro Francisco Tomás y Valiente UNED Alzira Valencia/Fundación Instituto de Historia Social, Valencia, 2000. También "Repartos de baldíos y realengos. La política de rehabilitación tras la guerra de los Diez Años" en Centro de Investigaciones de América Latina (comp.), De súbditos 
Desde la perspectiva de la historia ambiental, Reinaldo Funes ha desarrollado una línea de trabajo poco explorada en la historiografía sobre Cuba. El coste medioambiental de la vía escogida para el desarrollo plantacionista, las transformaciones generadas en la agricultura -en particular el impacto sobre los bosques y los conflictos surgidos en torno al control de los recursos naturales entre los objetivos metropolitanos-, la Marina Real y los intereses económicos insulares -el azúcar-, o entre estos últimos y la Inspección de Montes, organismo encargado de velar por el patrimonio rural del Estado. ${ }^{27}$ En una línea similar se encuentran el estudio de Mark Smith sobre el central Manatí -ubicado en la costa norte de la región oriental-, uno de los mayores latifundios estadunidenses establecidos en la isla en las primeras décadas del siglo XX. ${ }^{28}$

No podemos olvidar la importancia adquirida por las investigaciones que examinan el tema agrario desde el punto de vista de la sociología que incorpora información histórica de utilidad. Tal es el caso de Procesos agrarios en Cuba. 1959-1995, escrito por Juan Valdés Paz, acerca de las medidas adoptadas y las transformaciones agrarias llevadas a cabo después del triunfo de la revolución. Otro libro reciente se debe a un colectivo de autores encabezado por Carmen D. Deere, y que lleva por título Güines, Santo Domingo y Majibacoa, sobre sus historias agrarias. ${ }^{29}$

Por último, nos referiremos a los resultados de investigaciones más recientes por parte de científicos de España y Estados Unidos fundamentalmente. Entre los primeros sobresalen los trabajos de José Antonio Piqueras, Antonio Santamaría y Luis Miguel García. ${ }^{30}$ Los estudios de Piqueras han abierto una línea

del rey a ciudadanos de la nación, Publicacions de la Universitát Jaume I, Castellón, 2000, pp. 129147; "Asentar para dominar. Salamanca y la colonización militar. Cuba, 1889-1890", Tiempos de América, núm. 8, 2000, Castellón, pp. 29-46.

${ }^{27}$ Reinaldo Funes, "Los conflictos por el acceso a la madera en La Habana: hacendados versus Marina (1774-1815)" en José A. Piqueras (ed.), Diez nuevas miradas de historia de Cuba, pp. 67-90. Sobre los antecedentes y perspectivas de la historia ambiental en Cuba "Azúcar y deforestación. Una aproximación a la historia medioambiental en Cuba" en Manuel González de Molina y Juan Martínez Alier (eds.), Naturaleza transformada. Estudios de historia ambiental en España, Barcelona, 2001, pp. 183-209. Su tesis doctoral "Azúcar, deforestación y medioambiente. Los bosques en Cuba entre 1772 y 1926", presentada recientemente con éxito en la Universitát Jaume I, ha sido el primer estudio de estas características dentro de la historiografia cubana, abriendo un camino inexplorado hasta entonces.

${ }^{28}$ Véanse Mark Smith, "The political economy of sugar productions and environment of eastern Cuba, 1898-1923", Environment History Review, vol. 19, núm. 4, 1995, pp. 31-48. También el trabajo de Consuelo Naranjo, "Los reconocimientos madereros en Cuba (1780-1810)" en Manuel Lucena (ed.), El bosque ilustrado: estudios sobre la política forestal española en América, ICONA, Madrid, 1991, pp. 107-123, aporta información de utilidad para el tema que nos ocupa.

29 Juan Valdés Paz, Procesos agrarios en Cuba. 1959-1995, Ed. Ciencias Sociales, La Habana, 1997; Carmen D. Deere, Niurka Pérez et al., Güines, Santo Domingo y Majibacoa, sobre sus historias agrarias, Editorial Ciencias Sociales, La Habana, 1998.

${ }^{30}$ Véanse José Antonio Piqueras y Enric Sebastià, Agiotistas, negreros y partisanos. Dialéctica social en vísperas de la revolución gloriosa, Edicions Alfons El Magnànim/Institució Valenciana D'Estudis I Investigació, 1991, y “Capitales en el azúcar. Los hacendados ante la rentabilidad 
de investigación en relación con los problemas agrarios donde se imbrican la realidad metropolitana y la especificidad colonial. En el libro, Agiotistas, negreros y partisanos, escrito junto con Enric Sebastià, analizan cuestiones tales como el patrimonio real, la redención y venta de censos, las desamortizaciones a partir del decreto de Mendizábal, los compradores y, en general, las consecuencias sociales de este proceso. Asimismo, en un trabajo posterior al examinar los capitales del azúcar nos muestra una de las vertientes del crédito agrario. Por su parte, Santamaría y García nos introducen en el mundo de colonato, sus características y diversidad a partir de la relación con el uso y tenencia de la tierra. Santamaría, además, ha profundizado en el estudio del cultivo del azúcar en el siglo XX. La tierra ocupa un lugar destacable en los trabajos de este autor que clarifica y aporta datos novedosos sobre la extensión de las propiedades, área dedicada al cultivo, la relación entre la fase agrícola y la industrial, los trabajadores, etc. Su libro, Sin azúcar no hay país. La industria azucarera en la economía cubana (1919-1939), está llamado a cubrir un vacío importante en relación con la problemática agraria en la primera mitad de dicha centuria, dada la relativa carencia de estudios que aborden este periodo.

Por un camino similar discurren las investigaciones realizadas por Allan Dye acerca del establecimiento de los grandes centrales, la expansión de los latifundios estadunidenses en Cuba y la implantación de una economía de escala entre 1899 y 1929. Mientras que Laird Bergad regresa al tema azucarero en su libro Cuban Rural Society in the Nineteenth Century. The Social and Economic History of Monoculture in Cuba, un estudio novedoso que aporta al conocimiento de la industria y cultivo de la gramínea en el siglo XIX y nos ofrece datos pormenorizados para la provincia de Matanzas sobre la tenencia de la tierra, su uso, producción y la renta agraria. ${ }^{31}$

económica y la oportunidad de inversión (1878-1895)", Revista de Indias, vol. LVIII, núm. 212, 1998, pp. 163-193; Antonio Santamaría y Luis M. García Mora, "Colonos. Agricultores cañeros, ¿clase media rural en Cuba? 1880-1898", Revista de Indias, vol. LVII, núm. 212, 1998, pp. 131-161. También, "A propósito de la industria azucarera en Cuba (1860-1877): mano de obra y tecnología" en Michèle Guicharnaud-Tollius (ed.), Le Sucre. Dans L'espace caraïbe hispanophone, XIX et XX siécles, Reserches Amèriques layines, L' Harmattan/Universitè de Pau et des Pays de l'Adour, 1998, pp. 71-94. Véase, además, A. Santamaria, Sin azúcar no hay pais. La industria azucarera en la economía cubana (1919-1939), Universidad de Sevilla/CSIC/Diputación de Sevilla, Sevilla, 2002, y "Caña de azúcar y producción de azúcar en Cuba. Crecimiento y organización de la industria azucarera cubana desde mediados del siglo XIX hasta la finalización de la primera guerra mundial" en Consuelo Naranjo, Miguel A. Puig-Samper y Luis M. García (eds.), La nación soñada: Cuba, Puerto Rico y Filipinas ante el 98, Doce Calles, Madrid, pp. 225-250, "Intensificación y economías de escala. La transformación tecnológico-organizativa de la industria azucarera cubana después de la primera guerra mundial, 1919-1930" en História e tecnologia do açucar, Centro de Estudos de História do Atlântico/ Secretaría Regional do Turismo e Cultura, Regiâo Autónoma da Madeira, 2000, pp. 423-452. También el tema agrario es el objeto de investigación actual de Vicent Sanz en la Universitát Jaume I.

${ }^{31}$ Allan Dye, Cuban sugar in the age of mass production: technology and the economies of de sugar central, 1899-1929, Stanford University Press, Stanford/California, 1998; Laird W. Bergad, 


\section{FUENTES}

Para el estudio de la tierra en Cuba contamos con una amplia base documental, tanto en archivos y bibliotecas de ese país como en España. En el Archivo Nacional de Cuba existen numerosos fondos con información sobre la tierra. El fondo Intendencia de Hacienda contiene la documentación generada por dicha institución a partir de 1763-1764, fecha en que fue creada y comenzó a registrar toda actividad o fuente de ingresos a la administración, por lo que resultan imprescindibles para conocer el entramado fiscal. Dentro de la "Administración General Terrestre", los manuales de administración recogen información útil sobre los ingresos a nivel local, en la cual destacan los provenientes del patrimonio rural. Los libros sobre diezmos constituyen una de las mayores reservas de información para la historia agraria, sobre todo en relación con los tipos de arrendamientos, clases de finca, operarios, producción etc. Igualmente los libros de alcabalas nos informan sobre las compraventas de fincas, mientras que los padrones de renta líquida resultan imprescindibles en cualquier estudio. Son de obligada consulta los fondos Realengos, Gobierno general, Real Consulado de Agricultura y Junta de Fomento, Intendencia de Hacienda, Anotaduría de hipotecas, Reales órdenes y cédulas, Miscélaneas de expedientes, Bienes embargados, Bienes del Estado, Escribanías, Donativos y remisiones o Consejo de Administración, entre otros, pues aportan numerosos datos a cualquier investigación sobre la problemática agraria. ${ }^{32}$

En España, en el Archivo Histórico Nacional se encuentran los fondos U1tramar y Hacienda, que atesoran información sobre la Inspección de Montes y su labor en Cuba, la preocupación del Estado por validar su patrimonio en la isla, las usurpaciones de tierras, los repartos de terrenos y los intentos de asentar población fiel al poder español en las tierras de su propiedad. En el Archivo del Consejo de Estado se encuentran los expedientes elevados para consulta de esa institución que aportan datos sobre el proceso de desamortización. El Archivo de Indias en Sevilla, nos introduce en la problemática agraria de los siglos XVI, XVII y XVIII. En la sección de Manuscritos de la Biblioteca Nacional de Madrid, podemos examinar documentos referentes a los realengos, los bienes de regulares y las desamortizaciones.

Cuban Rural Society in the nineteenth century: the social and economic history of the monoculture in Matanzas, Princeton N. J., Princeton University Press, 1990.

${ }^{32} \mathrm{Al}$ respecto véanse Gloria García, Violeta Serrano y otros, Fuentes estadísticas para la historia económica y social de Cuba (1760-1900), Editorial Academia, La Habana, 1987, 2 tomos, y "La economía colonial: fuentes cuantitativas y reconstrucción histórica" en Aula de Cultura Iberoamericana (comp.), Nuestra común historia. Cultura y sociedad, Ciencias Sociales, La Habana, 1995, pp. 101110. En ese mismo volumen ver el trabajo de Fe Iglesias, "Fuentes cuantitativas para la historia económica y social de Cuba", pp. 111-124. 
También en Estados Unidos y en Alemania se encuentran documentos relacionados fundamentalmente con la industria azucarera y los latifundios. ${ }^{33}$ Por último, no podríamos dejar de mencionar cuatro fuentes esenciales: los diferentes censos levantados a lo largo de los siglos por las administraciones respectivas, las secciones de Mapas y Planos de cada uno de los archivos, de gran utilidad para el investigador a la hora de reconstruir las haciendas originales y su posterior demolición para dar paso a la agricultura comercial, el decrecimiento de las áreas boscosas, los asientos de los poblados y ubicación de las fincas, entre otras cuestiones de interés. Así como las Memorias de la Sociedad Económica de Amigos del País, que en busca de soluciones adelantan muchos de los problemas relacionados con la agricultura, y las fuentes periódicas, entre las que destacan la Revista de Agricultura del Círculo de Hacendados de la Isla de Cuba, la Revista Económica o el Boletín Oficial de Hacienda de la Isla de Cuba. ${ }^{34}$

\section{PERSPECTIVAS FUTURAS}

El examen de las cuestiones relacionadas con la tierra, los usos alternativos del suelo, los tipos de propiedad y aprovechamiento, los conflictos generados en torno a la titularidad del suelo así como la compraventa o reparto de terrenos, las formas de crédito, tanto para su adquisición como para la puesta en explotación de los predios rurales, los tributos y censos, entre otras cuestiones, ofrecen un vasto campo por explorar todavía.

La estructura agraria en los primeros siglos requiere de una revisión y ampliación de los postulados establecidos por Julio Le Riverend, desde estudios de casos que reconstruyan el proceso de subdivisión de las haciendas hasta investigaciones generales sobre las demoliciones, el avance del azúcar sobre las nuevas tierras, las formas de traspaso de la propiedad, la venta o el crédito. En este campo, las historias locales o regionales podrían contribuir al conocimiento general. Las diferentes figuras jurídicas así como los censos y gravámenes, esperan aún un análisis que clarifique y especifique sus funciones. Se tiende a desvirtuar sus propósitos y a confundir los tipos de censos con las ventas o el crédito, atendiendo a la especificidad colonial sin conocer o mencio-

${ }^{33}$ La documentación alemana ha sido trabajada fundamentalmente por Fe Iglesias, quien también ha utilizado, en el caso de las estadunidenses, The Lousiana Planter and Sugar Manufacturer (Nueva Orleans) o la Spanish Trety Claims Commission.

${ }^{34}$ Una recopilación de los principales Censos y otras fuentes estadísticas en Comité Estatal de Estadísticas, Los Censos de población y viviendas en Cuba. Estimaciones. Empadronamientos y Censos de población de la época colonial y la primera intervención norteamericana, Instituto de Investigaciones Estadísticas, La Habana, 1988, 2 vols. Sobre las Memorias de la SEAP véase Izaskun Álvarez Cuartero, Memorias de la Ilustración: las Sociedades Económicas de Amigos del País en Cuba (1783-1832), Real Sociedad Bascongada de Amigos del País, Delegación en Corte, Madrid, 2000 . 
nar su significado de acuerdo con las intenciones metropolitanas. Poco o nada conocemos de los costes de la tierra y las condiciones de los traspasos, las formas de apropiación legal o encubiertas y las condiciones estipuladas, y las condiciones en que se efectuaban las ventas de tierras.

Los terrenos públicos, baldíos y realengos o de propios y arbitrios, también esperan un estudio específico -al cual nos estamos dedicando- conjuntamente con las pugnas entre el Estado, los municipios, los hacendados -ganaderos versus azucareros- $\mathrm{y}$ los pequeños propietarios. La influencia y aplicación de las políticas agrarias de la Ilustración en la agricultura de fines del siglo XVIII y principios del XIX, o el proceso de desamortización de los bienes de regulares son también temas que no han sido abordados.

Si en el caso de los cultivos no azucareros los análisis históricos son escasos, lo mismo se podría decir de otros usos de la tierra como la ganadería y la explotación forestal, de ahí la importancia de los acercamientos históricos a formas de propiedad y explotación de la tierra fuera del ámbito de la economía de plantaciones azucareras. Tampoco podemos olvidar que el avance del azúcar y la ocupación de las tierras no sólo repercutió en su utilización por otros cultivos o la ganadería hipotecando y limitando su desarrollo, sino también en detrimento de la riqueza forestal y otros recursos naturales; en este sentido la historia mediomabiental tiene mucho que aportar al conocimiento de las cuestiones agrarias.

Asimismo, los estudios sobre la tierra nos remiten a los habitantes de las áreas rurales, aunque se ha avanzado en el conocimiento de algunos aspectos como la vida cotidiana, la inmigración de trabajadores o las formas de protesta de la población rural, aún quedan lagunas: el colonato es una de ellas, las condiciones de contratación de los trabajadores libres, salario, etc., son aspectos que también requieren de un examen pormenorizado. El balance además arroja un desnivel entre el conocimiento de los primeros siglos, el estado de la tierra en el siglo XIX, y el siglo XX, que es el menos trabajado.

Una vieja frase acuñada antaño por los hacendados azucareros y repetida en innumerables ocasiones por los productores reza: "sin azúcar no hay país"; permítasenos ampliarla, "sin tierra no hay país": un territorio eminentemente agrícola donde la mayoría de su población por espacio de más de tres siglos se ubicaba en las áreas rurales tiene una deuda pendiente con los estudios agrarios. Subsisten aún muchas interrogantes, los investigadores tienen ante sí un largo camino por recorrer. 